\title{
Retratos vivos de mamá: un proyecto de literatura web y escritura de duelo
}

Fecha de recepción: 8 de febrero de 2018

Fecha de aprobación: 15 de mayo de 2018

www.retratosvivosdemama.co es un proyecto de literatura web inspirado en el duelo: un duelo ocasionado por la muerte de mi madre, así como la posibilidad de superarlo a partir de la creación. Abordar el lenguaje desde el duelo significó liberar sensaciones de pérdida que tenía atoradas y que con la escritura permitieron reconfigurar lo que significó la muerte de mamá. Mi madre murió luego de sufrir una enfermedad que la consumió durante cinco años hasta convertirla, literalmente, en una piedra. Después de su muerte su presencia seguía en mi vida, dolorosa y letal a veces; alegre, nostálgica y consoladora otras, pero sobre todo con un carácter enigmático que me persigue hasta hoy y que rodea casi todo lo que pienso, siento y escribo. Nombrar el dolor, nombrar la muerte, decirlos una y mil veces hasta poderlos pasar por la garganta: así podría resumir la escritura de Retratos vivos de mamá. La escritura se me reveló como un espacio para encender y entender el silencio inexplicable que viene tras la pérdida de un ser querido, para trazar esa ausencia a través de una escritura visceral que se arriesga a delirar a veces, a recordar, a describir o a excavar en la memoria, en todo caso, una escritura que divaga y a la que la palabra escrita no le alcanza y por eso mismo recurre a otros medios artísticos para dejarla hablar.

Citar: López Jiménez, C. (enero-junio de 2018). Retratos vivos de mamá: un proyecto de literatura web y escritura de duelo. La Palabra,(32), 233-241. doi: https://doi.org/10.19053/01218530.n32.2018.8177
Carolina López Jiménez

Escritora quindiana-bogotana 
El proyecto ha ido creciendo con el tiempo desde que se publicó online en 2015 y espera continuar haciéndolo. Se trata de una obra con potencial transmedia que desde su gestación se ha propuesto explorar el entrecruce de géneros literarios y la inclusión de diversos medios artísticos como el dibujo, el video, el audio y la fotografía en un proyecto cuyo nervio es eminentemente literario. La versión hoy disponible en Internet es un piloto, pero un piloto que ofrece una experiencia de lectura completa desde ya.
Dada su estructura no lineal, Retratos vivos de mamá se puede leer de manera parcial o total. Compartimos una muestra de fragmentos en la revista La Palabra como una primera aproximación a su particular mixtura de lenguaje y estilo. Sin embargo, es en la versión online donde tendrán la verdadera experiencia de lectura que propone la obra. Pueden acceder de manera gratuita desde cualquier computador o dispositivo móvil para continuar con su lectura y conocer sus contenidos multimedia.

\section{INTRO}

Pero una y otra vez, en más ocasiones de las que puedo recordar, de noche ya en la cama, o en la calle, o al entrar en mi aposento, alli está ella; hermosa, vital, con su familiar expresión, su conocida risa; más cerca que cualquier otro ser vivo, iluminando nuestras vidas sin rumbo como una antorcha, infinitamente noble y deliciosa

para sus hijos

Virginia Woolf, Momentos de vida

Mi madre ha muerto. Emprendo un viaje al pasado para buscarla. Buscaré a esa mujer que fue antes de mí y de mi hermano. Buscaré a aquella que existió antes de conocer a mi padre; intentaré acceder a esa porción de vida de los padres que le será siempre ajena a sus hijos. No es una persecución esto que hago. Tampoco una huida. Han sido lentos y tranquilos los pasos dados.

Para ir al encuentro de mi madre, construyo caminos de letras, puentes con letras, mundos enteros con palabras. Y con imágenes, porque desde niña la imagen me ha buscado incansable: dibujos, fotos, revistas, pantallas, collages. Iré tras los rastros que dejó mi madre regados por la vida. Los recogeré a través de objetos y de voces. Sobre todo, buscaré las huellas que mi madre dejó en otros; lo haré con los recuerdos que mis tías y tíos tienen de ella. Preguntaré a la madre de mi madre, que aún vive y a los amigos, amigas y novios que tuvo alguna vez mamá. Volveré a recorrer los lugares que mi madre recorrió cuando era más joven de lo que soy yo ahora. No iré, como hizo el hijo de Pedro Páramo, a Comala. No. La hija de Lucy dejará quietos a los muertos; volverá hasta su madre a través de los vivos. Asomará un ojo hacia el pasado. Escuchará silenciosa. Tomará nota atenta de todo cuanto escuche y vea. Sacará las fotos de todos los álbumes. Y volverá al presente con su maleta llena de voces. Volverá para darle una segunda vida a la mujer que fue su madre antes de tener hijos. Inventará otra vida para su madre.

Torcerá el destino, los tiempos, las posibilidades. La hija fecundará todos esos recuerdos reunidos: recortará, bordará, grabará, hará dibujos y trazará líneas de sentido. Traerá los materiales que crea necesarios para que el relato de su madre niña y joven cobre vida.

Otros motivos reposan detrás de estas ventanas. Un deseo inmenso de salvarme: un poco para eso 
escribo también. Para desterrar el recuerdo de los días oscuros que precedieron a la muerte de mi madre, para sacudirme la inmovilidad e impotencia de los últimos años en la casa de mi familia materna. Para quitarle el manto de agonía a la memoria de mi madre. Ha pasado un buen tiempo desde entonces, aunque a ratos parezca como si no: la carne viva, moscas rondando, gusanos que carcomen, elegías inmunes, imágenes extáticas, rezos, súplicas entre los brazos, piedras rotas, golpes secos, respiros ahogados, llantos, insomnios, ruegos, forcejeos, gargantas frenadas.

He decidido no enterrar ese tiempo bajo tierra para olvidarlo. Prefiero, en cambio, fundar otro recuerdo para mantener viva la memoria de mi madre. $Y$ libre. Le reinventaré un pasado. Preguntaré lo que jamás se me ocurrió preguntarle en vida. Desataré todas las preguntas que nacieron cuando mi madre se fue. Haré todo lo que antes no pude o no supe hacer.

Los padres tuvieron siempre una vida antes de sus hijos. Pocas veces tenemos esto en cuenta. Cuántas cosas guardadas del pasado de una persona. Qué cantidad de kilómetros añadían a mi madre todas las cosas que calló, cuán lejana la hacía todo aquello que nunca supe de ella. ¡Hasta dónde llegaría el dolor del pozo de su alma! ¿Cuánta lama cargan los sueños dejados a un lado por dedicarse a construir una familia? Y qué tipo de caparazón debe crear la piel para aguantar el golpe de una realidad edificada con montañas de frustración.
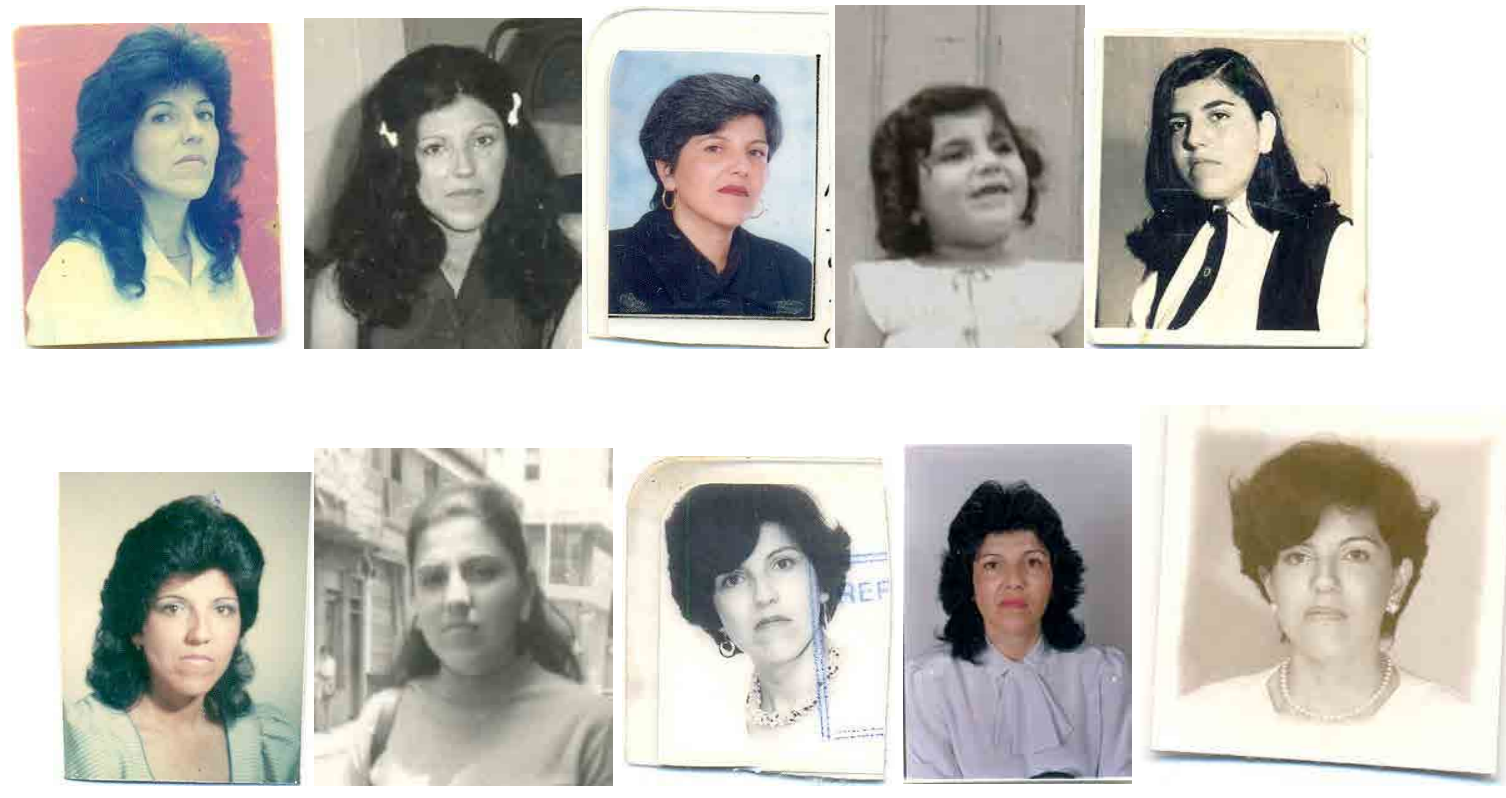

Dos cosas me quedan hoy: la certeza de no haber sabido nunca leer a mi mamá y el consuelo de haber intentado comprenderla al final de sus días. Y de haberla acompañado. Qué privilegio poder iluminar la imagen de una persona con algunos de sus rostros pasados. Cuánta vida y explosión de movimiento genera la muerte: cuántas preguntas y deseo por responderlas.
Ningún final definitivo para esta historia. Muchos inicios. Tan sólo la decisión clara de escalar el duelo, este duelo que nació con la muerte de mi madre. El camino hacia ella no hace más que revelarme pasos para llegar hasta mí. Aún después de muerta sigue ayudando a construir aquello que soy. Y sigo. Me visita en sueños. Cuánto la quiero: ¡imposible conjugar el verbo en pasado cuando pienso en ella! Avanzo con ritmos discontinuos. 
También con pausas y silencios que se estiran. Y entre más clara es la invención del personaje de mi madre, más borroso es el recuerdo doloroso que tengo de ella. No paro. No aún. Me reviso. Descubro cuánto de ella habita en mí y cuánto de mí pongo en ella cuando escribo. Fue mi madre quien me enseñó a escribir. La llevo en los gestos de mi mano. También en los trazos fuertes de mis huesos.

En mis clavículas pronunciadas puede verse la silueta de mamá. No en la forma de la cara ni en mis rasgos duros. Sí en la manera en la que busco una palabra en el diccionario. Tengo sus abrigos -que me pongo a veces-y sus mismos brazos largos. El pelo grueso y abundante. Un corazón abierto al mundo. Prefiero llevarla así, puesta en lo que soy. No más hablarle ni prenderle velas. Llevar sí, en mi pecho, la antorcha que ella encendió y que se mantiene viva. Y el grito de mujer. Es hora de dejarla descansar.

\section{https://www.retratosvivosdemama.co/introduccion}

\section{CUARTO OSGURO}

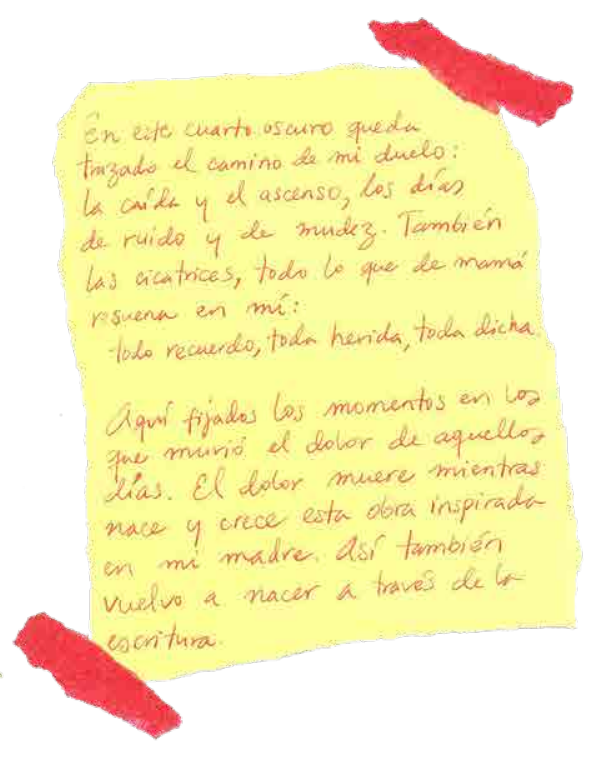

En este cuarto oscuro queda trazado el camino de mi duelo: la caída y el ascenso, los días de ruido y de mudez. También las cicatrices, todo lo que de mamá resuena en mí, todo recuerdo, toda herida, toda dicha.

Aquí fijados los momentos en los que murió el dolor de aquellos días. El dolor muere mientras mi nace y crece esta obra inspirada en mi madre. Así también vuelvo a nacer a través de la escritura.

\section{https://www.retratosvivosdemama.co/cuarto}

\section{DIARIO DE PUELO}

Diciembre 2 de 2013 / Residencia en la tierra. Montenegro, Quindío. El dolor estuvo de visita en mi familia. Se aferó a mi madre, tuvimos que ver cómo se la iba consumiendo. El dolor crecía y mi madre se iba disminuyendo. El dolor se alimentaba de ella, la exprimía. Las fuerzas de mamá aniquiladas. Se hizo trozos. Luego polvo. Humo. Cenizas. Todo se nos volvió terrible. Durante el tiempo que siguió a la muerte de mi madre todas las imágenes que de ella vivían en mí eran letales. Cerré mis cuadernos. Hice un gran silencio y me agarré de él con las uñas.

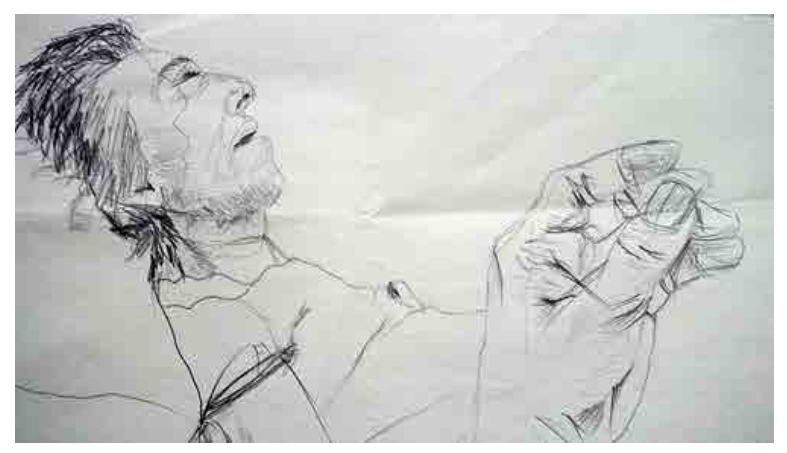

La punzada seguía viva, podía sentirla haciendo nido en mi corazón. Necesitaba construir otro re- 
cuerdo. Necesitaba borrar el sabor doloroso de los últimos años. Necesitaba lavarme el horror que tenía pegado en el cuerpo. Mamá merecía que se le recordara de otro modo. Mamá, cuya vida había sido mucho más que los días de enfermedad.

¿Y qué era lo que mamá había sido?

El día de la cremación y durante los meses siguientes se me acercó mucha gente a hablarme de ella.

¿Quién era ese personaje del que me hablaban? ¿Reconocía en él a mi mamá?

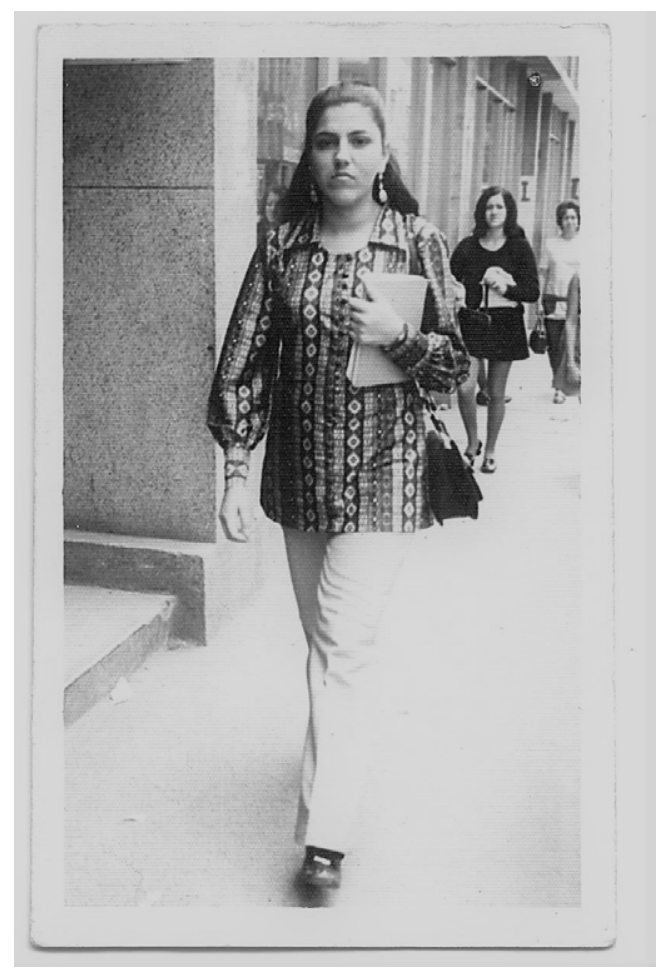

Mi madre

sin hijos aún

Del álbum saltan

hasta mí

todos sus anhelos

\section{Diciembre 13 de 2013}

Nunca

Nunca

Como si me acabaran de presentar esa palabra que tan mal he usado durante toda la vida.

Cuántas veces pronuncié nunca sin saber lo que decía nunca nunca nunca y ahora aparece con su severidad. Transparente nunca. Nunca como un golpe seco nunca, contundente nunca, nunca más su voz. No más el tronco grueso que sostuvo al fruto, del que se agarraron la rama y la raíz nunca; nunca más la sombra fresca, sí, pero también avasallante que no deja ver el sol nunca, nunca, nunca más el sí de siempre nunca.

De ahora en adelante mis días, hasta el último, tendrán un nunca hecho de carne: nunca más volveré a verla nunca abrazarla nunca el calor de su cuerpo ni la tibieza nunca de su corazón ni las risas infantiles nunca. Un nunca acuñado en mi vida, prueba tajante de lo que ya no está, de lo que no será, encarnación de un jamás que ha hecho nido en la sala de mi casa, en mi mesa de noche, en todos los bolsillos de mis pantalones, en la billetera, en la silla del bus nunca.

Nunca lanzado con la cadena de la contundencia por el hecho de no haber sido elegido nunca. No un nunca más volveré a fumar, nunca lo perdonaré, nunca volveré a hablarle, no. No se trata de esos nuncas menos implacables, retorcibles, maleables. Este es un nunca recto, horizontal y expansivo. Irrompible nunca. Nunca que golpea como hierro en la cara y en los huesos y en lo más profundo de la piel por siempre nunca.

Julio 27 de 2013 


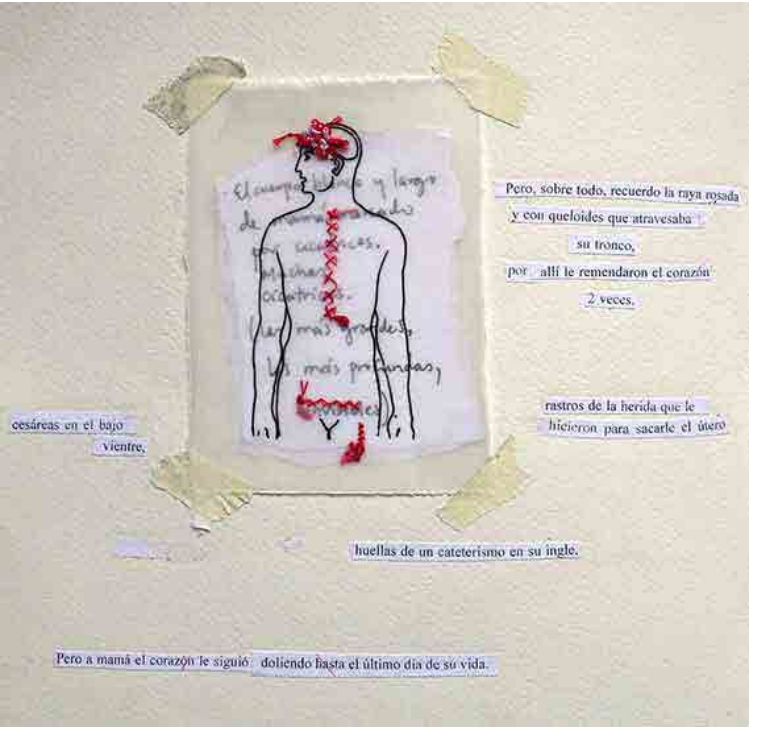

El cuerpo blanco de mamá marcado por cicatrices: cesáreas en el bajo vientre, huellas de un cateterismo en su ingle, rastros de la herida que le hicieron para sacarle el útero por el que el cáncer había empezado a entrar. Pero, sobre todo, recuerdo la línea rosada y con queloides que atravesaba su tórax: empezaba arriba del ombligo y subía casi hasta llegar al cuello. Por allí le remendaron el corazón dos veces. Pero a mamá el corazón le siguió doliendo hasta el último día de su vida. Por lo menos eso me pareció siempre.

\section{Marzo 6 de 2014}

¿Qué de mamá conservo, qué rechazo, qué de su imagen me encadena? ¿cómo quitarme las mordazas si ni siquiera sé muy bien cuándo me las puso? Siento el cuerpo apretado, la soga invisible atada a mí. Y una linterna de miedos, también miedos en un costal roído por los años.

Heredé sus miedos, muchos de ellos. Desde que era muy pequeña supe leer en su rostro la tristeza, la insatisfacción, el llanto callado de mamá. Y siempre asocié ese paisaje triste (el paisaje en el que yo solía verla) a nosotros, a su vida de familia.

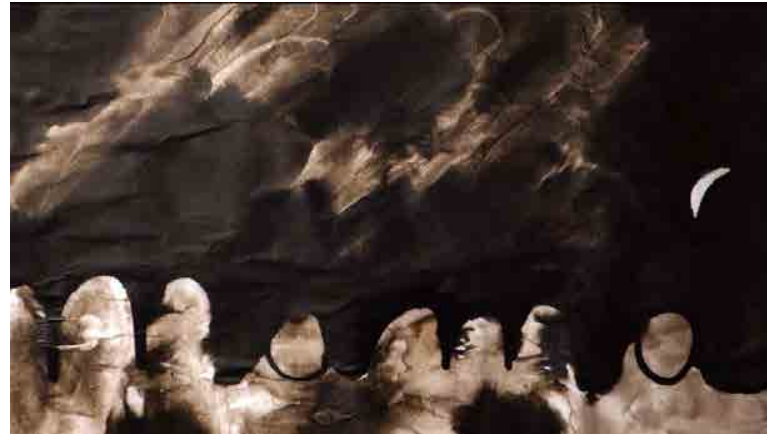

\section{Junio 13 de 2013}

m-a-m-á.

Esa palabra no nacerá más que en mi boca y se quedará allí para jamás volverse acto. No podrá ser en mí ni dentro de mí. La tendré en mi boca, sí. La cuidaré entre mis manos, la escribiré sobre todas las superficies que conozca para no dejar que muera. Pero no será en mí.

Diré mamá hasta la muerte desde la orilla de la hija: nunca en la playa de la madre.

Pronunciaré madre como quien dice luna: la miraré del mismo modo. Jamás el viaje hasta la noche las estrellas siempre desde lejos mis pies plantados sobre el suelo fértil sin las ansias locas que en mi vientre no llegaron a nacer.

\section{Agosto 21 de 2014}

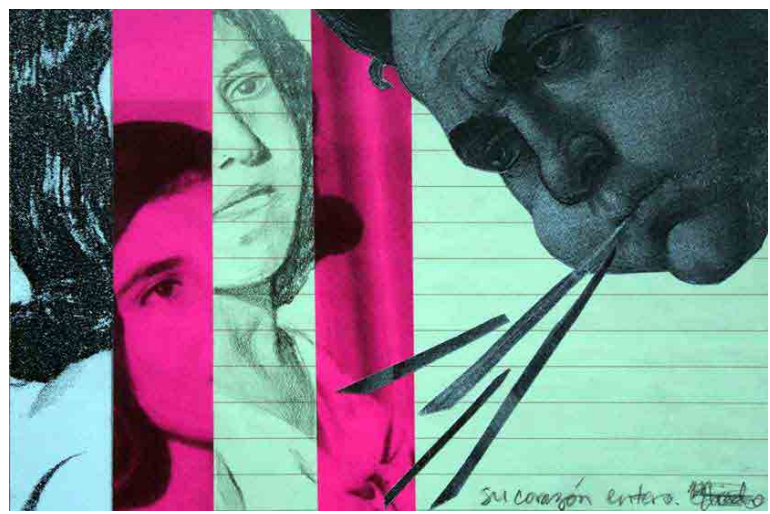


https://www.retratosvivosdemama.co/cuarto/ diariodeduelo

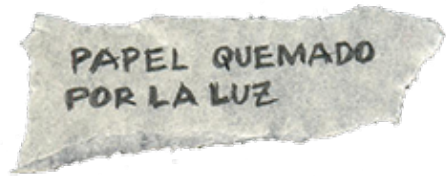

Mamá ha muerto. De ahora en adelante tendré que ser mi propia madre.

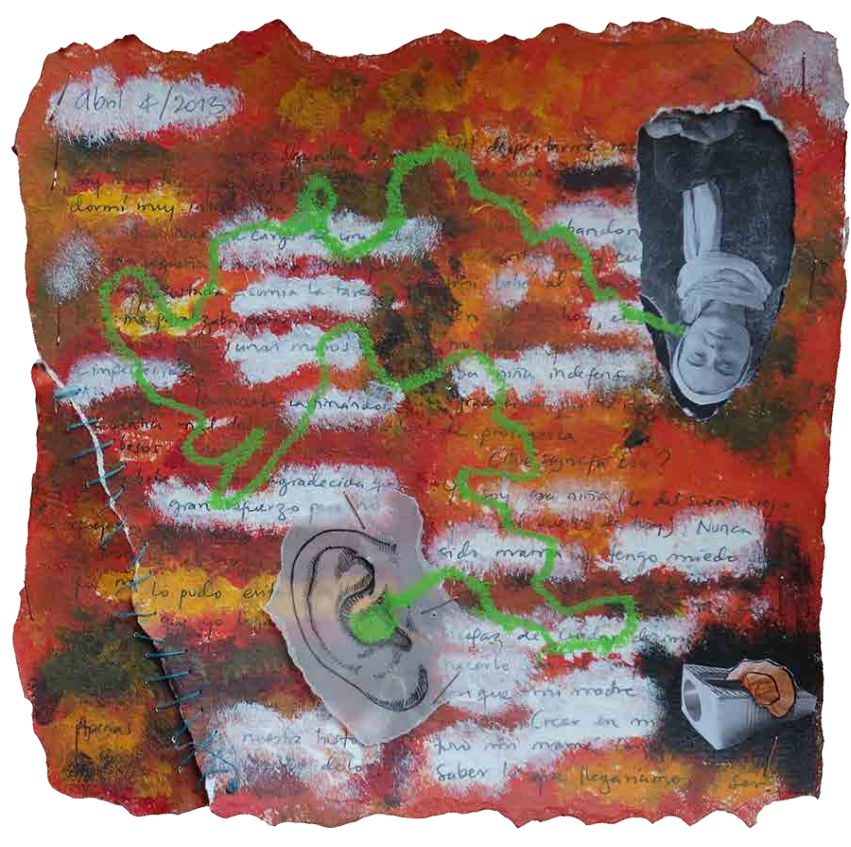

Muchos seres me aman todavía, pero desde ahora mi muerte no matará a ninguno. Ahi está lo пиеvо.

Roland Barthes, Diario de duelo

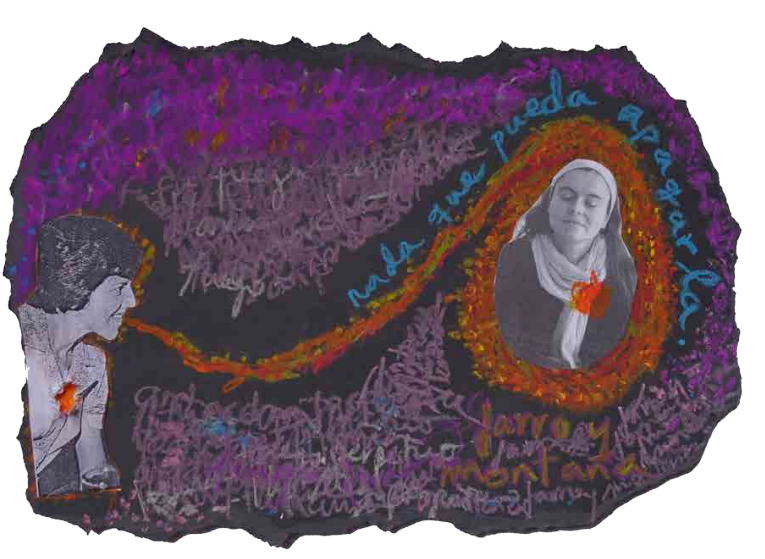

Escribo.

Siento arder en mí el fuego perpetuo de mi madre. Me oriento con la antorcha que llevó mi abuela un día. En mí se incendia la llama de todas las nacidas en el mundo (antes y después).

Nada que pueda apagarla

\section{https:/www.retratosvivosdemama.co/cuarto/ papelquemadoporlaluz}

\section{CARRETE DE RECUERDOS}

Aquí las fotos arrancadas de los álbumes familiares de mi madre. Relámpagos del tiempo de Lucy y de los que estuvieron más cerca de ella. Aquí algunas de sus once hermanas y de sus ocho hermanos. Aquí Inés Delgado de Jiménez, su madre, y José Jesús Jiménez Yépez, su padre. Aquí sus amigos y amigas. Aquí sus sonrisas de colegio, sus silencios, sus enigmas de niña. Su pelo a la cintura de joven. Aquí algunos lugares que habitó. Algunas de sus caras. Aquí las huellas de su cuerpo tan capaz de ser una cosa y otra, de su cuerpo camaleón ahora inexistente. 
la palabra
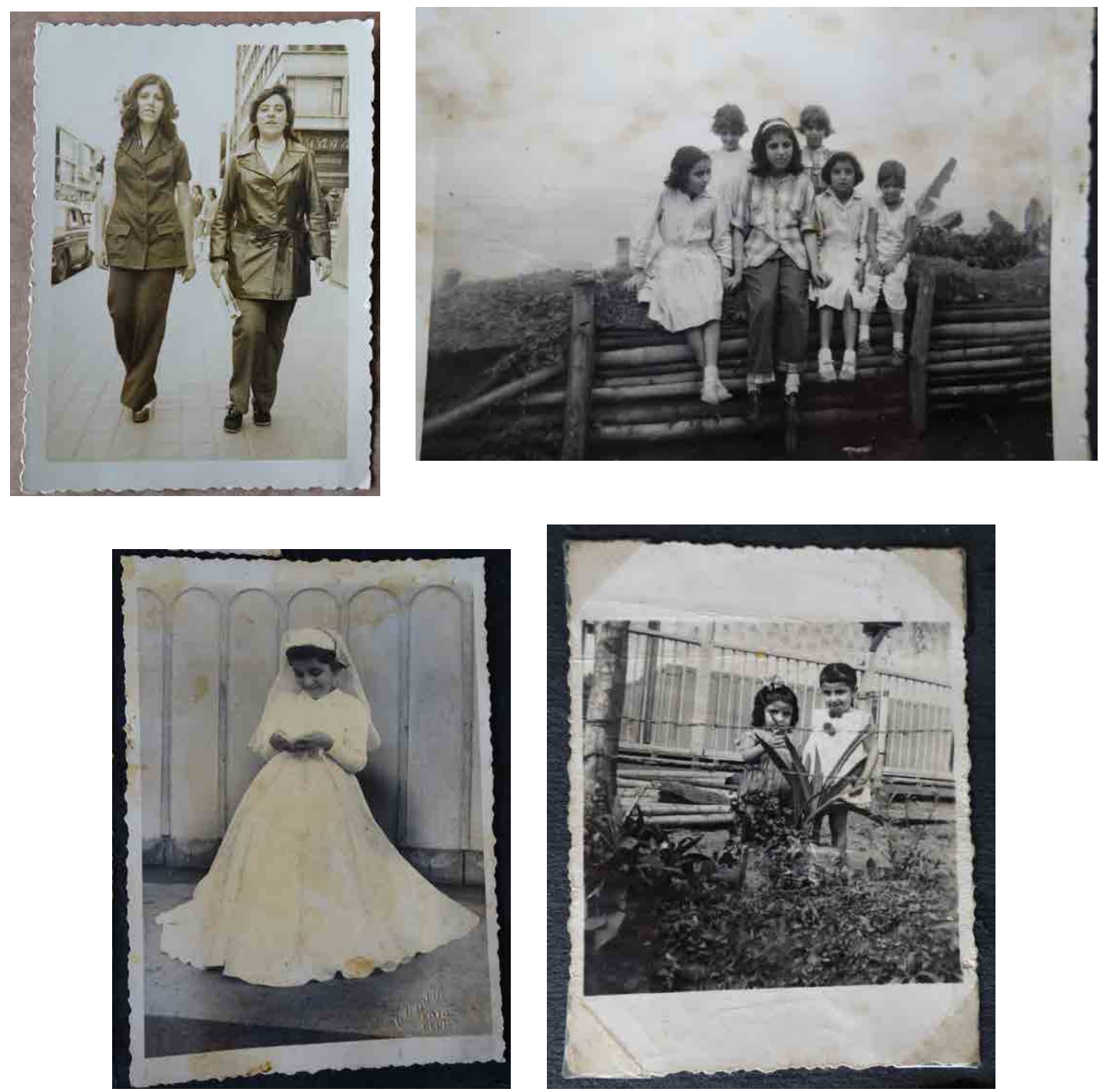

https://www.retratosvivosdemama.co/cuarto/carrete

\section{CRÉDITOS}

Carolina López Jiménez es la autora de www.retratosvivosdemama.co. El proyecto ha sido fruto de un trabajo colectivo e interdisciplinario entre:

\section{Carolina López Jiménez}

Idea original / Textos / Desarrollo artístico / Dirección artística del proyecto.

\section{Fabio José Polanco Gaona}


Edición de video y edición de textos / Apoyo en el concepto editorial y en la dirección artística del proyecto.

\section{Martha Hernández}

Diseño y Dirección de arte del website. (www.muyvisual.org)

\section{Rafael Díaz}

Desarrollo web. (www.muyvisual.org) 
